\title{
Lysozyme Activity in Cystic Fibrosis
}

\author{
WALTER T. HUGHES, ${ }^{(21)}$ BERYL A. KOBLIN, AND BERYL J. ROSENSTEIN
}

Eudowood Divisions of Infectious Diseases and Pulmonary Diseases, Department of Pediatrics, The Johns Hopkins University School of Medicine, Baltimore, Maryland, USA

\section{Summary}

The activity of lysozyme in saliva and serum was determined in 51 patients with cystic fibrosis. Measurements were made on two occasions at least 1 month apart and compared to those of 25 normal healthy individuals of the same ages, sex, and race.

The mean serum lysozyme activity of normal individuals was 5.8 $\mu \mathrm{g} / \mathrm{ml}(\mathrm{S} . \mathrm{E} .=0.4)$, whereas that of cystic fibrosis patients was $10.8 \mu \mathrm{g} / \mathrm{ml}($ S.E. $=0.5)$. The difference is significant $(P<0.05)$. Initial mean values compared to those of repeated samples from the cystic fibrosis group were similar, whereas individual fluctuations occurred between test periods.

The mean lysozyme activity of the saliva sample of normal individuals was $63.5 \mu \mathrm{g} / \mathrm{ml}($ S.E. $=9.3)$ and the mean value from cystic fibrosis patients was $82.7($ S.E. $=6.9)$. This difference was not significant $(P>0.1)$. Mean values from specimens obtained a month or longer after the initial saliva samples were similar for the two episodes.

There was no correlation between the serum and salivary values and the age, sex or race of the subjects, the Shwachman-Kulczycki scores, colonization with Pseudomonas aeruginosa, Staphylococcus aureus or Haemophilus influenzae or absolute white blood cell counts.

In vitro studies failed to demonstrate bactericidal activity for mucoid and nonmucoid strains of $P$. aeruginosa or for $S$. aureus.

\section{Speculation}

Elevated lysozyme activity in cystic fibrosis may be related to either an increased granulocyte turnover because of chronic bacterial infection of the respiratory tract or to a basic defect in the lysosomal membrane allowing an increased release of the enzyme, or a combination of both.

The lysosomal enzyme, muramidase (lysozyme), is well-known for its bacteriolytic activity. The substrate is a mucopolysaccharide of certain bacterial cell walls, the beta-linked alternating copolymer of $N$-acetylglucosamine and $N$-acetylmuramic acid. In Alexander Fleming's original description of lysozyme, lysis was observed with some strains of streptococci and staphylococci but not with B. pyocaneus (Pseudomonas aeruginosa) (9). The enzyme is widely distributed in nature and human tissues. The role lysozyme plays in man's defense against bacterial infection has never been elucidated; however, bacterial infections clearly affect the release of lysozyme activity of blood neutrophils (13). Because of the unique susceptibility of individuals with cystic fibrosis to certain bacterial infections we investigated the lysozyme activity in the serum and saliva of these patients.

Cystic fibrosis is characterized by chronic colonization of the respiratory tract with Staphylococcus aureus and $P$. aeruginosa. No host determinant has been satisfactorily identified to explain this unusual flora or the episodic pulmonary infections experienced by these patients.

There is evidence suggesting that a lysosomal defect may be a basic derangement in cystic fibrosis. In 1970 Bartman et al. (2), with ultrastructure studies, observed an increase in the number and size of lysosomes in cultured fibroblasts from cystic fibrosis patients. Also, the activity of $\alpha$-glucosidase, a lysosomal enzyme that degrades glycogen, has been found to be increased in the lysosomes of cultured lymphoid cells obtained from patients with cystic fibrosis as compared with normal controls (1). More recent studies with skin fibroblasts suggest that leakage from intracellular to extracellular sites occurs with multiple lysosomal enzymes (15). In comparison with normal cells, the fibroblasts from cystic fibrosis homozygotes had lower intracellular activities of acid phosphatase, alpha-fucosidase, alpha-mannosidase, alpha-galactosidase, beta-galactosidase, hexosaminidase, $\alpha$-glucosidase and beta-glucosidase whereas the extracellular activities of the same enzymes were all above normal. Furthermore, the extra- and intracellular alkaline phosphatase values were increased. Elsewhere, high levels of $N$-acetyl- $\beta$-D-glucosamidase, $\beta$-glucouronidase, $\beta$-glucosidase, and alpha-galactosidase, and somewhat lower levels of alphamannosidase and alpha-fucosidase were obtained for the fibroblasts cultured from cystic fibrosis patients as compared to normal controls (4). Sera from cystic fibrosis homozygotes and heterozygotes were found to promote lysosomal degranulation of sensitized human leukocytes, as measured by enzyme release to a greater extent than normal sera (6). Considerable controversy has evolved from studies of cystic fibrosis fibroblasts and the multiple leakage of hydrolytic enzymes in that findings of some investigators have not been reproduced by others, possibly because of differences in technical methods (8). Although the studies on skin fibroblasts have been challenged $(10,19,20)$, the concept of a "leaky lysosome" defect cannot be discounted. On this premise one might expect to find increased activity of lysozyme in the sera and other body fluids in cystic fibrosis. In turn, this enzyme might play a role in the ecology of the bacterial flora and the infection of these patients. In earlier studies, elevated lysozyme activity was demonstrated in duodenal and gastric secretions in cystic fibrosis (12), whereas values from saliva were not significantly different than from normal individuals $(12,17)$.

The concentration of lysozyme activity in plasma represents a balance between the enzyme supplied from various cellular sources and the rate of catabolism. Disintegration of neutrophils, the monocyte-macrophage system and other enzyme-producing tissues are potential contributors to the plasma pool. Clearance can be attributed to degradation of the enzyme in tissues and catabolism of lysozyme molecule by the kidneys (14); thus, the plasma concentration represents a measure of the enzyme activity that is reasonably steady in the normal host. An abnormality in production or clearance might be reflected by an increase or decrease in values of the plasma concentration. Lysozyme activity in saliva represents the elaboration from tissues of a specific exocrine system.

In a prospective study we quantitated the lysozyme activity in serum and saliva collected from a group of stable-state cystic fibrosis patients on two separate occasions and compared these values to those from a group of normal individuals.

\section{MATERIALS AND METHODS}

Subjects. Fifty-one patients with cystic fibrosis were studied in a prospective manner. Informed consent was obtained for both 
study-group and control patients. They were afebrile, experiencing a stable course and without evidence of acute infectious episodes. Serum and mixed saliva specimens were collected at the same time. One month, or longer, after the first study, 40 of the 51 patients had the studies repeated. Twenty-five normal individuals, matched for age, sex and race, served as controls and were studied in the same manner as the cystic fibrosis patients, except that repeat studies were not done.

For saliva collection, the patient rinsed the mouth three times with water and after $10 \mathrm{~min}$ with nothing by mouth saliva was expectorated into a sterile plastic container. At least $5.0 \mathrm{ml}$ was collected. Five $\mathrm{ml}$ of whole blood was collected in a sterile vacutainer; allowed to clot; then after centrifugation at $1000 \times g$ for $20 \mathrm{~min}$ the serum was removed. This specimen and the saliva were stored immediately at $-70^{\circ} \mathrm{C}$ until the time of the assay.

On each study day the cystic fibrosis patients had sputum cultures obtained for bacteria. The clinical status of the patients was estimated by the Shwachman-Kulczycki scoring system (18). Serum precipitins to $P$. aeruginosa, serotypes 2,3 , and 4 were identified by both counterimmunoelectrophoresis and Ouchterlony plates using soluble antigens prepared by the method of Danneman and Michael (7). Absolute granulocyte, lymphocyte, and monocyte values were calculated from the total white blood cell counts and differential percentages.

Lysozyme assay. The lysozyme assay was performed by the method of Litwack (16). The enzyme and the substrate, Micrococcus lysodeikticus, were obtained from Worthington Diagnostics, Freehold, NJ. The lysozyme standard was prepared with distilled water in concentrations from $2.0-20.0 \mu \mathrm{g} / \mathrm{ml}$ and aliquots of 0.6 $\mathrm{ml}$ mixed with the bacterial substrate. The change in absorbance of the solution between $30-180 \mathrm{sec}$ at $550 \mathrm{~nm}$ was recorded for each lysozyme concentration using a B \& L Spectronic 20 spectrophotometer. From these data a standard curve was constructed. The same procedure was followed for undiluted serum and diluted saliva samples. The activity of the sample was calculated from the standard curve.

Bacteriolytic activity of lysozyme for $S$. aureus and $P$. aeruginosa. Isolates of $S$. aureus and $P$. aeruginosa, mucoid, and nonmucoid variants, obtained from cystic fibrosis patients were tested for susceptibility to lysozyme hydrolysis. Colonies from overnight cultures were suspended in distilled water to an optical density of $0.3 \mathrm{~mm}$ at $550 \mathrm{~nm}$. Lysozyme concentrations ranging from $2-40$ $\mu \mathrm{g}$ per $\mathrm{ml}$ were prepared in distilled water. Aliquots of $0.6 \mathrm{ml}$ of each lysozyme concentration was added to the bacterial substrate and the change in absorbance of the solution between 30-180 sec at $550 \mathrm{~nm}$ was determined by spectrophotometer in the same manner as for Micrococcus lysodeikticus described in the lysozyme assay.

\section{RESULTS}

Characterization of subjects studied. Ages ranged from 5-33 years $($ median $=13 \mathrm{yr}$ ). Thirty were males. Shwachman-Kulczycki scores ranged from 32-92 (median $=76$ ). Sputum cultures obtained on the initial and the repeat visit showed that $39(80 \%)$ of the patients harbored $P$. aeruginosa, $29(64 \%)$ had $S$. aureus and $16(32 \%)$ had Haemophilus influenzae in the respiratory tract during the study. Thirty-one $(62 \%)$ of the patients had serum precipitins to one or more of the $P$. aeruginosa, serotypes 2,3 , or 4. The mean total white blood cell count was 10,633 per $\mathrm{mm}^{3}$ granulocyte count was 7,211 per $\mathrm{mm}^{3}{ }^{3}$ lymphocyte count was 2,488 per $\mathrm{mm}^{3}{ }^{3}$ and monocyte count was 630 per $\mathrm{mm} .^{3}$

The control group included 25 healthy individuals ranging in age from 5-24 years (median $=11$ yr). Twelve were males. Only one of the 25 controls had serum precipitins to $P$. aeruginosa and this consisted of a faint band to one antigen. Blood counts were not done in this group since normal values are well-established.

Serum lysozyme. The mean lysozyme activity of the sera from the 25 normal individuals was $5.8 \mu \mathrm{g} / \mathrm{ml}($ S.E. $=0.4 \mu \mathrm{g} / \mathrm{ml}$ ), with $95 \%$ confidence limits of $4.97-6.67 \mu \mathrm{g} / \mathrm{ml}$.

The 91 serum samples from 51 cystic fibrosis patients had mean lysozyme activity of $10.8 \mu \mathrm{g} / \mathrm{ml}($ S.E. $=0.5)$, with $95 \%$ confidence limits of $9.57-11.8 \mu \mathrm{g} / \mathrm{ml}$. The initial specimens from the 51 patients had a mean lysozyme value of $10.7($ S.E. $=0.49) \mu \mathrm{g} / \mathrm{ml}$ At least 1 month later 40 of the patients were tested again and the mean value was $10.9 \mu \mathrm{g} / \mathrm{ml}$ (S.E. $=0.9$ ). The correlation coefficient between the first and second samples was 0.172 , which was not significant at $P=0.05$.

The difference between the mean serum lysozyme values for the normal and cystic fibrosis groups was significant at $(P<0.05$ (Student's $t$ test). This was also true within sexes.

Salivary lysozyme. The mean lysozyme activity of the saliva samples from the 25 normal subjects was 63.5 (S.E. $=9.3) \mu \mathrm{g} / \mathrm{ml}$ with $95 \%$ confidence of $44.4-82.7 \mu \mathrm{g} / \mathrm{ml}$.

The mean lysozyme value for 91 saliva samples from 51 cystic fibrosis patients was 82.7 (S.E. $=6.9) \mu \mathrm{g} / \mathrm{ml}$, with $95 \%$ confidence limits from $66.2-95.3 \mu \mathrm{g} / \mathrm{ml}$. The first specimens from the 51 patients had a mean value of $82.6($ S.E. $=9.1) \mu \mathrm{g} / \mathrm{ml}$. One month or more later 40 of the patients were retested and the mean value for salivary lysozyme was found to be 82.8 (S.E. $=10.7) \mu \mathrm{g} / \mathrm{ml}$.

Comparison of the normal and cystic fibrosis groups revealed no significant difference between mean salivary lysozyme values by the Student's $t$ test $(P>0.1)$.

The levels of serum activity were unrelated to salivary activity of lysozyme.

Comparison of clinical features with lysozyme values. There was no correlation between either serum or saliva lysozyme levels and the age, sex, or race of the cystic fibrosis patients. Comparison was made to the Shwachman-Kulczycki scores to determine if there was a relationship between the clinical status of the patients and lysozyme activity; however, no significant differences were observed when groups with scores of 100 to 86,85 to 71,70 to 56 , 55 to 41 , or 40 and less, were compared for serum and saliva lysozyme levels. Those patients colonized with $S$. aureus, $P$. aeruginosa or $H$. influenzae had lysozyme activity similar to those who were not colonized. Also, there were no significant differences between those patients with and without precipitins to $P$. aeruginosa.

The serum and salivary lysozyme levels were similar for counts above and below the means for absolute granulocytes, lymphocytes, and monocytes; however, these counts were in the range expected for normals.

Effect of lysozyme on bacterial isolates. Isolates of $S$. aureus and mucoid and nonmucoid strains of $P$. aeruginosa from cystic fibrosis patients were not lysed with as much as $40 \mu \mathrm{g} / \mathrm{ml}$ of lysozyme. This was approximately four times the mean serum levels of the enzyme in the cystic fibrosis patients. Furthermore, a mucoid and nonmucoid isolate of $P$. aeruginosa were carried through five passages in broth culture (trypticase soy broth) with $300 \mu \mathrm{g} / \mathrm{ml}$ of lysozyme. No bactericidal activity was demonstrated and the isolates retained the respective mucoid and nonmucoid characteristics when subsequently cultured in cetrimide agar (Pseudocel, PBL).

\section{DISCUSSION}

Although the serum activity of lysozyme is significantly increased in patients with cystic fibrosis, the enzyme does not have bacteriolytic activity against $S$. aureus and $P$. aeruginosa strains as evidenced by in vitro tests as well as the persistence of these organisms in patients with high levels of lysozyme in both serum and saliva. Two possible explanations for the high serum levels can be proposed: (1) an increased granulocyte turnover secondary to chronic bacterial infection of the respiratory tract or (2) a basic defect in the lysosomal membrane permitting an increased release of the enzyme. It is also possible that both factors are in effect There is reason to believe that lysozyme may indirectly affect bacterial infection through a mechanism other than microbial lysis. In recent studies by Gordon et al. (11) lysozyme, as a product of inflammatory cells, was shown to function in a negative feedback system to modulate the inflammatory response. These investigators found that human lysozyme greatly suppressed chemotactic motility of human polymorphonuclear leukocytes and inhibited the burst of hexose monophosphate shunt metabolism as well as 
the production of superoxide anion by stimulated neutrophils. Significant inhibition of chemotactic motility was observed over lysozyme concentrations from $10-1000 \mu \mathrm{g} / \mathrm{ml}$. In the cystic fibrosis patients, $53(58 \%)$ of the 91 serum specimens had lysozyme concentrations of $10 \mu \mathrm{g} / \mathrm{ml}$ or greater (range $=3-40 \mu \mathrm{g} / \mathrm{ml}$ ) whereas only $2(8 \%)$ of the 25 control sera had values of $10 \mu \mathrm{g} / \mathrm{ml}$ (range $=3-10 \mu \mathrm{g} / \mathrm{ml}$ ) and none were greater. By the inhibition of neutrophil migration, lysozyme may both limit further neutrophil accumulation and suppress the activity of phagocytes already present at the inflammatory site. These effects could permit the survival of $S$. aureus and $P$. aeruginosa at invasive sites. It is well known that despite specific antibiotic therapy to which the organisms are sensitive, $P$. aeruginosa cannot be eradicated from the respiratory tract flora of patients with cystic fibrosis. This emphasizes the fact that clearance mechanisms en toto cannot accomplish removal of these organisms from the colonized respiratory tract. The inhibitory or regulatory effects of lysozyme on the alveolar macrophage, the major phagocyte of the lung, have not been studied. Comparison of alveolar macrophages and neutrophils from rats has shown that these alveolar macrophages contain 10fold-greater intracellular concentrations of lysozyme and release more lysozyme after stimulation than blood neutrophils (3).

An alternative explanation for the increased serum lysozyme activity in cystic fibrosis follows the "leaky lysosome" hypothesis. On this premise one would expect a rather constant extracellular release of lysosomal enzyme to the tissue fluid and serum. If this is a defect in cystic fibrosis an increase in serum lysosomal enzymes should be unrelated to infection, granulocyte turnover, and the severity of the disease as rated by the Shwachman-Kulczycki scores. The lack of these relationships in this study lends support to this explanation. Serum activity of the enzyme would not necessarily be constant because the extent of clearance might vary. On the other hand, the lack of correlation between lysozyme activity in sequential samples from each patient with cystic fibrosis shows that the high lysozyme activity is not maintained in a steady state, a pattern more likely to result from episodic influences such as low-grade bacterial infections.

Certain acknowledgements must be made. Although the association of bacterial infection with cystic fibrosis has been wellestablished, the hypothesis for the "leaky lysosome" defect requires further substantiation. Inasmuch as our study demonstrated elevated serum lysozyme activity in cystic fibrosis patients, a similar response may occur with chronic lung disease of other etiology. Although the assay for lysozyme is considered to be specific for the enzyme, exhaustive studies have not been done to exclude the influence of unidentified enzymes or other products that might lyse $M$. lysodeikticus. Also, the use of mixed saliva specimens might have obscured differences in specific salivary gland excretions (5).

This study has demonstrated elevated serum lysozyme activity in cystic fibrosis as compared to normal individuals of similar age, sex, and race. The mechanism responsible for this difference was not determined but may be due to either an increase in granulocyte turnover or a basic defect in the lysosome.

\section{REFERENCES AND NOTES}

1. Antonowicz, I., Sippell, W. G., and Shwachman, H.: Cystic fibrosis: lysosomal and mitochondrial enzyme activities of lymphoid cell lines. Pediatr. Res., 6: 803 (1972)

2. Bartman, J., Weismann, U., and Blanc, W. A.: Ultrastructure of cultivated fibroblasts in cystic fibrosis of the pancreas. J. Pediatr., 76: 430 (1970).

3. Bigger, W. D. and Sturgess, J. M.: Role of lysozyme in the microbial activity of rat alveolar macrophages, Infect. Immun., 16: 974 (1977).

4. Butterworth, J., Scott, F., McCrae, W. M., and Bain, A. D.: Lysosomal enzymes of cultured fibroblasts of cystic fibrosis patients. Clin. Chim. Acta, 40: 139 (1972).

5. Chernick, W. S., Eichel, H. J., and Barbero, G. J.: Submaxillary salivary enzymes as a measure of glandular activity in cystic fibrosis. J. Pediatr., 65: 694 (1964).

6. Conod, E. J. Conover, J. H., and Hirschhorn, K.: Demonstration of human leukocyte degranulation induced by sera from homozygotes and heterozygotes for cystic fibrosis. Pediatr. Res., 9: 724 (1975).

7. Danneman, P. J. and Michael, J. G.: Reaginic antibody production to protein antigens of Escherichia coli and Pseudomonas aeruginosa by mice. Infect. Immun., 14: 694 (1976).

8. Davis, P. B. and DiSant'agnese, P. A.: A review: cystic fibrosis at $40-$ Quo Vadis? Pediatr. Res., 14: 83 (1980).

9. Fleming, A.: On a remarkable bacteriolytic element found in tissues and secretions. Roy. Soc. Proc., B93: 306 (1922).

10. Gibbs, G. E. and Griffin, G. D.: Activity in skin components of children with cystic fibrosis. Science, 167: 993 (1970)

11. Gordon, L. I., Douglas, S. D., Kay, N. E., Yamada, O., Osserman, E., and Jacob, H. S.: Modulation of neutrophil function by lysozyme. J. Clin. Invest., 65: 226 (1979).

12. Green, M., Kulczycki, L. L., Nemer, M., Blume, S., and Shwachman, H.: Lysozyme levels in cystic fibrosis of the pancreas. Amer. J. Dis. Child., 97: 303 (1959).

13. Hanson, N. E. and Andersen, V.: Lysozyme activity in human neutrophilic granulocytes. Brit. J. Haematol., 24: 613 (1973).

14. Hanson, N. E.: Plasma lysozyme-a measure of neutrophil turnover, an analytical review. Ser. Haematol., 7: 1 (1974).

15. Hösli, P. and Vogt, E.: Cystic fibrosis: leakage of lysosomal enzymes and of alkaline phosphatase into the extracellular space. Biochem. Biophys. Res. Comm., 79: 741 (1977).

16. Litwack, G.: Photometric determination of lysozyme activity. Proc. Soc. Exper. Biol. Med., 89: 401 (1955).

17. Mandel, I. D., Kutscher, A., Denning, C. R., Thompson, R. H., and Zegarelli, E. V.: Salivary studies in cystic fibrosis. Amer. J. Dis. Child., 113: 431 (1967).

18. Shwachman, H. and Kulczycki, L. L.: Long-term study of one hundred five patients with cystic fibrosis: studies made over a five-to-fourteen year period. Amer. J. Dis. Child., 96: 6 (1958).

19. Wilson, R. G.: The activities of some acid hydrolases in the skin of patients with cystic fibrosis of the pancreas. Clin. Chim. Acta, 36: 113 (1972).

20. Riordan, J. R., Wychik, L., and Buchwald, M.: The induction of alkaline phosphatase in four matched pairs of normal and CF fibroblasts. p. 86. Cystic Fibrosis Club Abstracts, Rockville, Md., 1978.

21. Requests for reprints should be addressed to: Dr. Walter T. Hughes, Division of Infectious Diseases, St. Jude Children's Research Hospital, 332 N. Lauderdale, Memphis, TN 38101

22. Supported by Grant HL 19157, National Heart, Lung and Blood Institute, National Institutes of Health and by the Board of the Hospital for the Consumptives of Maryland.

23. Received for publication December 12, 1980.

24. Accepted for publication April 19, 1982. 